\title{
Center Impedance Method for Damping Measurement
}

\author{
D. Malogi, ${ }^{1}$ A. Gupta, ${ }^{1}$ and G. R. Kathawate ${ }^{2}$ \\ ${ }^{1}$ Department of Mechanical Engineering, Vibration and Acoustics Center, Northern Illinois University, DeKalb, IL 60115, USA \\ ${ }^{2}$ The Daubert Chemical Company, 4700 S. Central Avenue, Chicago, IL 60115, USA
}

Correspondence should be addressed to A. Gupta, gupta@ceet.niu.edu

Received 3 June 2009; Revised 5 October 2009; Accepted 18 November 2009

Recommended by Kim Meow Liew

Damping materials are used extensively for reduction of vibration and noise. These damping materials have viscoelastic characteristics and are used by automotive and other industries. Testing of these materials is important in order to predict their performance and traditionally the damping properties are measured by the Oberst method. This paper discusses an alternate method called the Center Impedance method where force and response are measured directly and the damping properties are obtained. The Center Impedance method is easy to use requiring only standard vibration equipment for excitation, namely, shaker, and is easy to control the experiment for repeatability. Results of beams tested by both Oberst and Center Impedance methods are presented in order to validate this test method.

Copyright ( 2009 D. Malogi et al. This is an open access article distributed under the Creative Commons Attribution License, which permits unrestricted use, distribution, and reproduction in any medium, provided the original work is properly cited.

\section{Introduction}

Damping is of the utmost importance for noise and vibration harshness issues related to the automotive industry [1]. Traditionally the Oberst method is the method of choice recommended by both ASME [2] and SAE [3]. Other innovative methods, such as inverted shaker, have been proposed $[4,5]$ but did not gain acceptance due to its limitation of applicability in low frequency ranges. However, the Oberst method poses two problems: (1) only viscoelastic materials sprayed or coated onto beams made of magnetic materials can be tested, and (2) heavily damped beams cannot be tested since the force and response sensors are non contacting magnetic sensors. The Oberst method is suitable primarily for narrow samples and wider samples requiring shaker use. This has led to various industrial standards $[6,7]$. The Center Impedance method [8], while based on the same theory as Oberst, overcomes both limitations associated with Oberst testing. The Center Impedance method does not require presence of a magnetic material and it provides direct measurement of force and response that permits the user to apply the necessary exciting force. It may be noted that the Center Impedance method is slowly gaining recognition [8-10] but a comprehensive study comparing the Center Impedance method and the Oberst method is so far lacking. Dowling and Saha [11] have studied loss factors by the Oberst and the Center Impedance methods (only at room temperature). They did not study the Young's moduli and, consequently, could not compare the accuracy of these methods based on comparison of predicted and measured natural frequencies. It may be noted that a platebased method called Giger Plate method [12] has existed in the industry. However, this method is not very useful [13] because it provides output only at one frequency (around $160 \mathrm{~Hz}$ ) and the measurement is based on a $6 \mathrm{~mm}$ thick plate which is uncommon in many industries, including automotive industry.

\section{Theory}

The Oberst method uses a cantilever specimen and two magnetic sensors (one placed close to the fixed end and the other placed close to the free end) are used for excitation and response (Figure 1). The Center Impedance method (Figure 2) typically uses an impedance head (force and acceleration sensor combined) to measure applied force and response acceleration of the free-free beam driven at the 


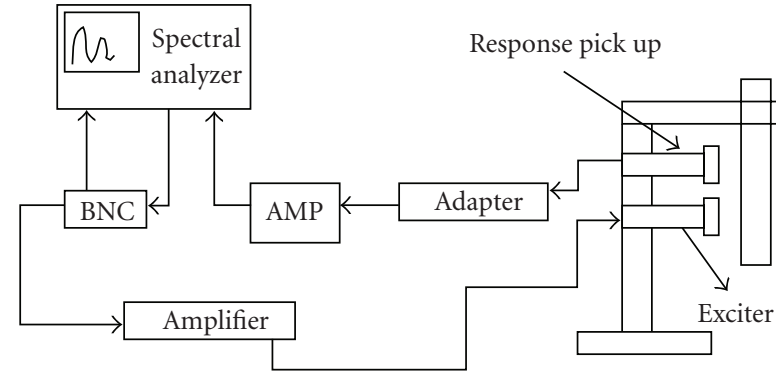

FIgURE 1: Oberst Setup.

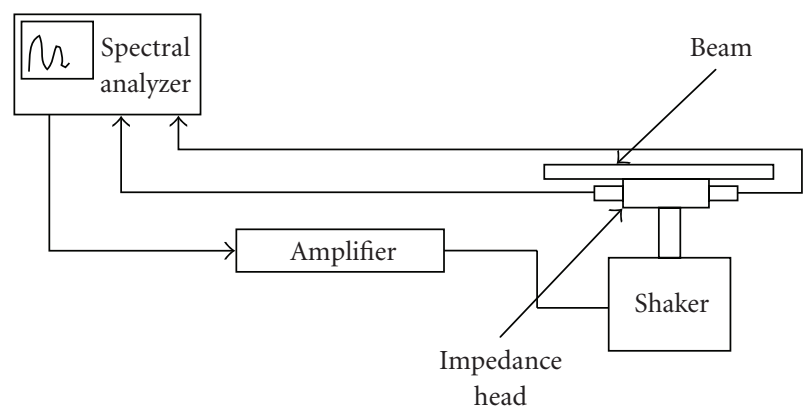

Figure 2: Center Impedance Setup.

center. Since almost all laboratories involved with vibration testing have shakers and impedance heads (or separate force sensor and accelerometer), the Center Impedance method does not require any special apparatus whereas the Oberst method requires a specialized Oberst fixture. Since the properties of the damping material are highly temperature sensitive, tests at temperatures higher than room temperature are performed inside an oven as shown in Figure 3.

The equations for the Oberst method specified in ASTM E756-93 [2] are based on Ross-Kerwin-Ungar (RKU) equations [14]. For a two-layer beam this leads to the following equations:

$$
\begin{aligned}
E_{1}= & {\left[(\alpha-\beta)+\left((\alpha-\beta)^{2}-4 T^{2}(1-\alpha)\right)^{1 / 2}\right] \frac{E}{2 T^{3}}, } \\
\eta_{1}= & (1+M T)\left(1+4 M T+6 M T^{2}+4 M T^{3}+M^{2} T^{4}\right) \\
& \times \frac{\eta_{c}}{M T\left(3+6 T+4 T^{2}+2 M T^{3}+M^{2} T^{4}\right)} .
\end{aligned}
$$

Since the above equations are applicable for a bar damped on one side, the same equations are applied for Oberst and Center Impedance methods (the effects of different boundary conditions are taken care of by natural frequencies of bare bars as well as damped bars).

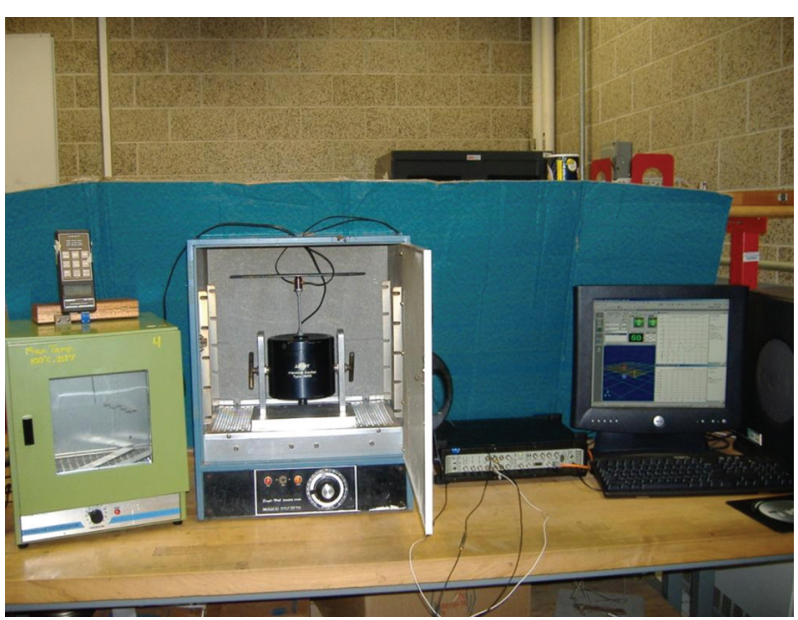

Figure 3: Center Impedance test setup inside Oven.

TABLE 1: Frequencies of bare bar for odd numbered modes.

\begin{tabular}{llc}
\hline $\begin{array}{l}\text { Theoretical frequency } \\
(\mathrm{Hz})\end{array}$ & $\begin{array}{l}\text { Frequency by Center } \\
\text { Impedance method }(\mathrm{Hz})\end{array}$ & Error \\
\hline 42.5 & 43.5 & $2.4 \%$ \\
230.4 & 225.5 & $2.1 \%$ \\
571.0 & 569.0 & $0.4 \%$ \\
1084.0 & 1071.0 & $1.2 \%$ \\
\hline
\end{tabular}

Table 2: Specifications of thin bars used for Oberst and Center Impedance.

\begin{tabular}{lcc}
\hline BATCH & R 690-64 & R 690-64 \\
\hline Beam type & Oberst & Center impedance \\
Boundary condition & Cantilevered & Free-Free \\
Material density & $1057\left(\mathrm{~kg} / \mathrm{m}^{3}\right)$ & $1057\left(\mathrm{~kg} / \mathrm{m}^{3}\right)$ \\
Material thickness & $0.00318 \mathrm{~m}$ & $0.0030 \mathrm{~m}$ to $0.004 \mathrm{~m}$ \\
Beam length & $0.2 \mathrm{~m}$ & $0.305 \mathrm{~m}$ \\
Beam width & $0.0127 \mathrm{~m}$ & $0.0305 \mathrm{~m}$ \\
\hline
\end{tabular}

Theoretical calculations to determine the natural frequencies for bare or undamped beams are based on the following equations:

$$
f_{n}=\left(\frac{1}{2 \pi}\right)\left(\beta_{n} l\right)^{2} \sqrt{\frac{E I}{\rho A l^{4}}}
$$

where $\beta_{n}=$ the $n$th modal eigenvalue parameter and its magnitude depends on the boundary conditions of the beam [15].

The natural frequencies measured by the Center Impedance method are compared with the theoretical values in Table 1. The first mode shape obtained numerically (by Finite Element software Ansys displayed on left) and by Center Impedance method (displayed on right) is shown in Figure 4. Similarly third bending mode (theoretical and experimental) is shown in Figure 5. 


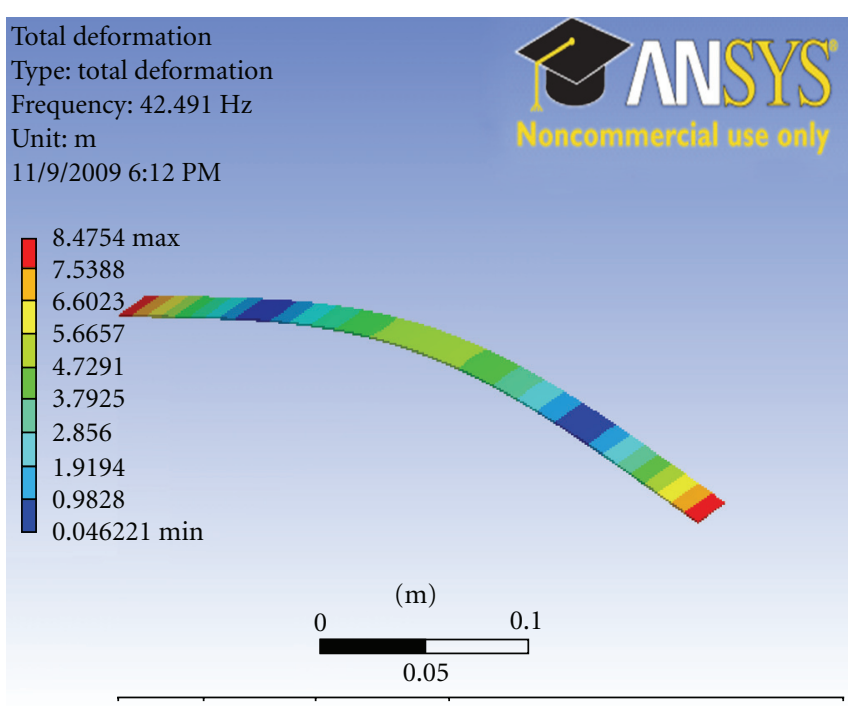

(a)

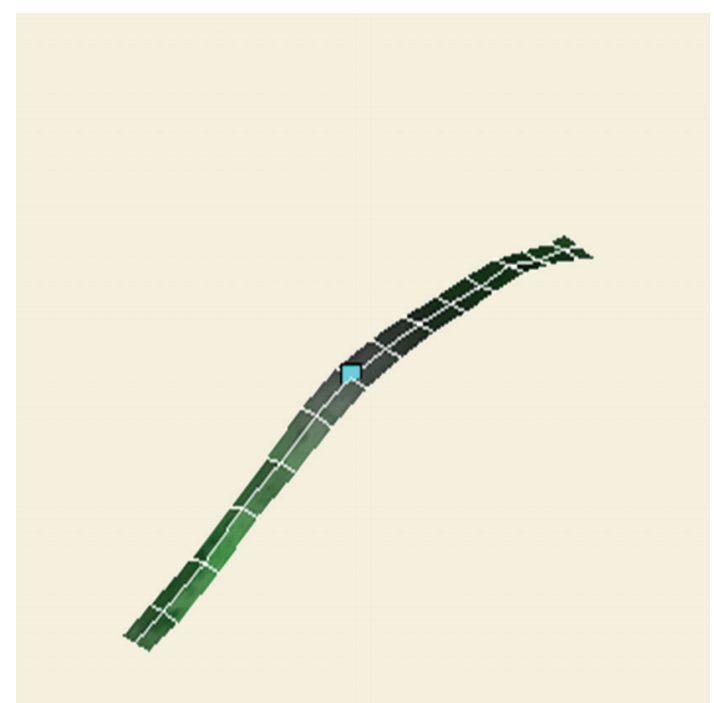

(b)

FIgURE 4: First bending mode at $42.5 \mathrm{~Hz}$ (theoretical) and $43.5 \mathrm{~Hz}$ (experimental).

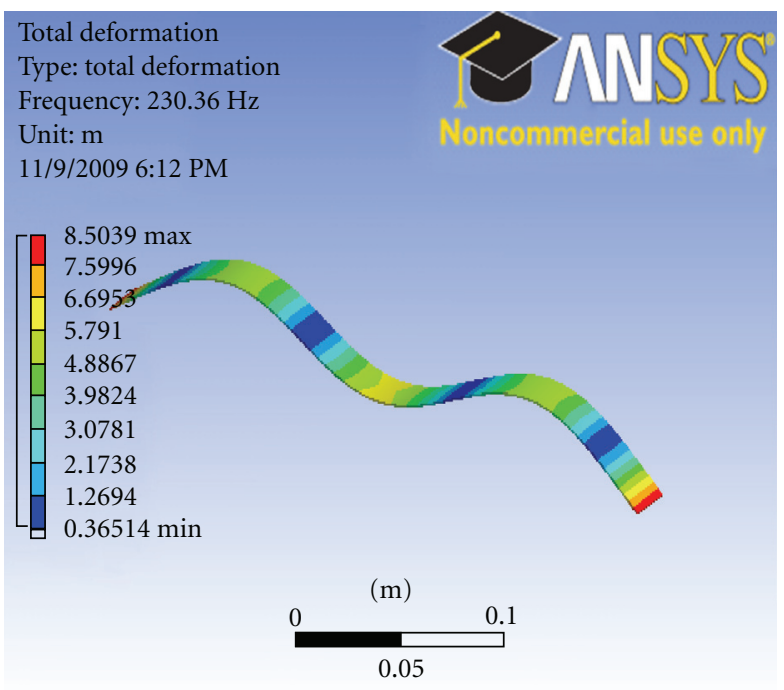

(a)

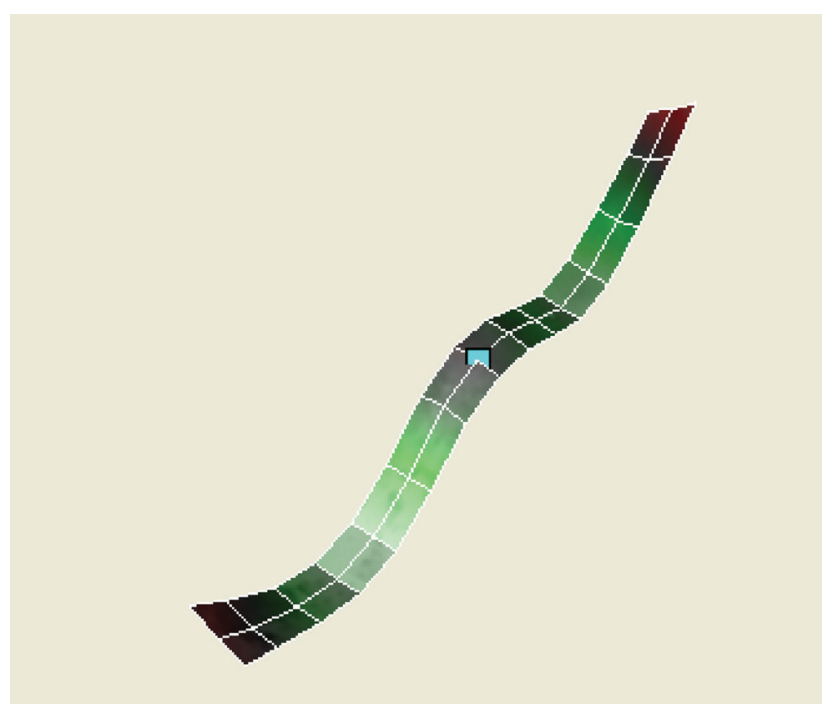

(b)

Figure 5: Third bending mode at $230.4 \mathrm{~Hz}$ (theoretical) and $225.5 \mathrm{~Hz}$ (experimental).

It may be noted that the Oberst setup involves fixedfree or cantilevered boundary conditions; whereas the Center Impedance method involves free-free boundary conditions. Since cantilevered boundary conditions are difficult to achieve, it is suggested to ignore the results involving the first mode [2]. The Center Impedance method, on the other hand, involves a boundary condition easier to simulate in experiment but only odd number modes are excited (due to placement of a stinger at the center). Natural frequencies by either method are obtained by the location of peaks of the transfer functions. Damping properties (loss factors) may be estimated by one of the three methods: Half power method, Schroeder integration (decay method), and power injection method [16]. In this study half-power method is used because it works well for transfer functions with wellseparated peaks and it is simpler than the Schroeder method. The power injection method has not been used because the previous studies $[16,17]$ have shown that the power injection method may produce erroneous results.

\section{Results}

Steel beams coated with liquid sprayable dampers with specifications, as shown in Table 2, were used for this study. Figures 6, 7 and 8 show the composite loss factors $\eta_{c}$ of the beams measured at room temperature, $40^{\circ} \mathrm{C}$ and $60^{\circ} \mathrm{C}$.

Next the material loss factor $\eta_{1}$ is computed based on (2), and the results are plotted in Figures 9, 10, and 11. 
TABle 3: Frequencies (in $\mathrm{Hz}$ ) of thick bars at room temp.

\begin{tabular}{|c|c|c|c|c|c|c|}
\hline Bar & Mode no. & $\begin{array}{l}\text { Experimentally } \\
\text { Observed } \\
\text { frequencies }\end{array}$ & $\begin{array}{l}\text { Frequencies based } \\
\text { on Young's } \\
\text { modulus from } \\
\text { Center Impedance }\end{array}$ & $\begin{array}{l}\text { Error for Center } \\
\text { Impedance }\end{array}$ & $\begin{array}{l}\text { Frequencies based } \\
\text { on Young's } \\
\text { modulus from } \\
\text { Oberst }\end{array}$ & $\begin{array}{l}\text { Error for } \\
\text { Oberst }\end{array}$ \\
\hline R690-64 S.no 4 & 1 & 110 & 115.4 & $5 \%$ & 311.8 & $183 \%$ \\
\hline R690-64 S.no 4 & 3 & 614.5 & 616.6 & $0.4 \%$ & 1690 & $175 \%$ \\
\hline R690-64 S.no 5 & 1 & 115 & 111.3 & $3 \%$ & 311.3 & $179 \%$ \\
\hline R690-64 S.no 5 & 3 & 633.5 & 615.3 & $3 \%$ & 1687 & $166 \%$ \\
\hline R690-64 S.no 6 & 1 & 115 & 113.5 & $1 \%$ & 308 & $167 \%$ \\
\hline R690-64 S.no 6 & 3 & 633.5 & 627.3 & $1 \%$ & 1675 & $164 \%$ \\
\hline 3wk R690-64 40 Deg & 1 & 129 & 128 & $0.8 \%$ & 303.9 & $135 \%$ \\
\hline 3wk R690-64 40 Deg & 3 & 680 & 708 & $4 \%$ & 1649.7 & $142 \%$ \\
\hline 4wk R690-64 40 Deg & 1 & 120.2 & 109.8 & $9 \%$ & 303.9 & $153 \%$ \\
\hline 4wk R690-64 40 Deg & 3 & 663.2 & 608 & $8 \%$ & 1649.7 & $149 \%$ \\
\hline
\end{tabular}

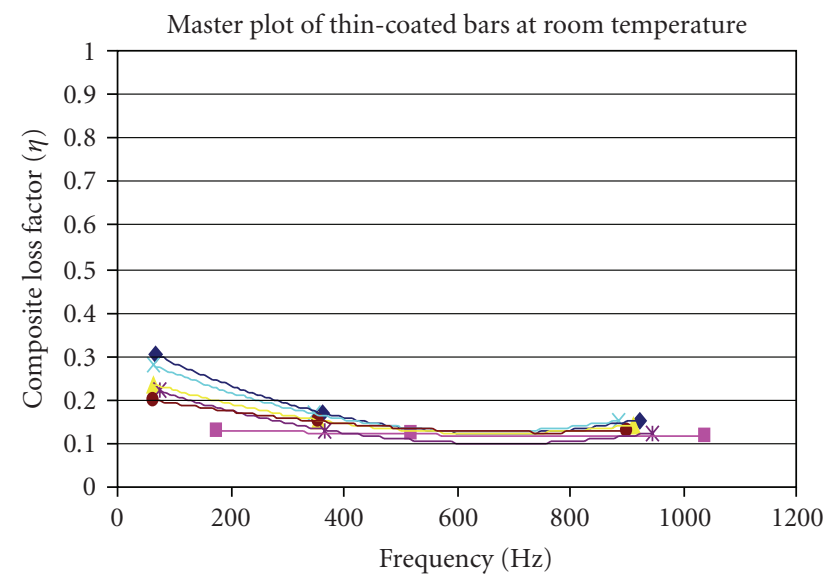

- R690-64 no.1 center impedance

- R690-64 oberst data

$\triangle$ R690-64 no.2 center impedance

$\times$ R690-64 no.3 center impedance

* R690-64 3 wk 40 deg 2 mm center impedance

- R690-64 4 wk 40 deg 2 mm center impedance

Figure 6: Composite loss factors for thin-coated bars at room temperature.

It may be noted that at any given frequency such as $200 \mathrm{~Hz}$, as expected thicker coating of damping material (bar R690-64 S.No2) will provide larger loss factor than that by bar with thinner coating (bar R690-64 S.No1) for a particular temperature as shown in Figure 12.

Since the loss factors as obtained by the Center Impedance method are consistently higher than those measured by the Oberst method, next Young's moduli of the materials were computed which would then be used to estimate the natural frequencies of thick coated bars and compare with the frequencies obtained by the experiment. Young's moduli of the material were computed using (1) and they are plotted in Figures 13, 14 and 15.

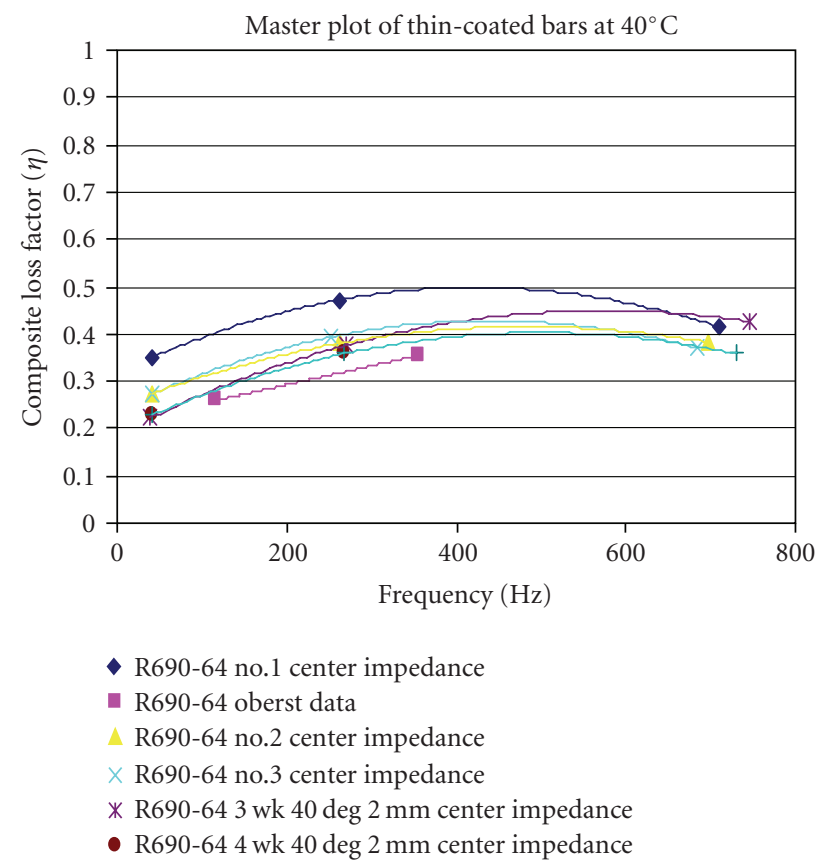

Figure 7: Composite loss factors for thin-coated bars at $40^{\circ} \mathrm{C}$.

Next, these moduli were used to compute the natural frequencies of bars coated with the same material but of different thicknesses $(0.0059 \mathrm{~m}$ to $0.0062 \mathrm{~m}$ nominal) and were compared with experimentally observed values as shown in Table 3.

\section{Conclusion and Discussion}

This paper shows the measurement of loss factor and Young's modulus of damping materials using the Center Impedance method. The Center Impedance method not only provided the loss factors which are higher, but more importantly provided Young's moduli which were in better 


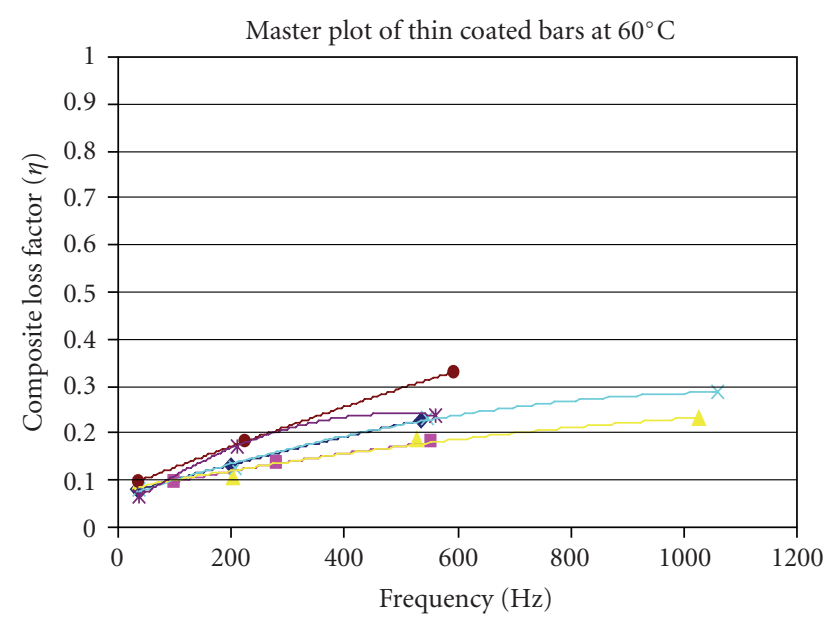

- R690-64 no.1 center impedance

- R690-64 oberst data

$\triangle$ R690-64 no.2 center impedance

$\times$ R690-64 no.3 center impedance

* R690-64 3 wk 40 deg 2 mm center impedance

- R690-64 4 wk 40 deg 2 mm center impedance

Figure 8: Composite loss factors for thin-coated bars at $60^{\circ} \mathrm{C}$.

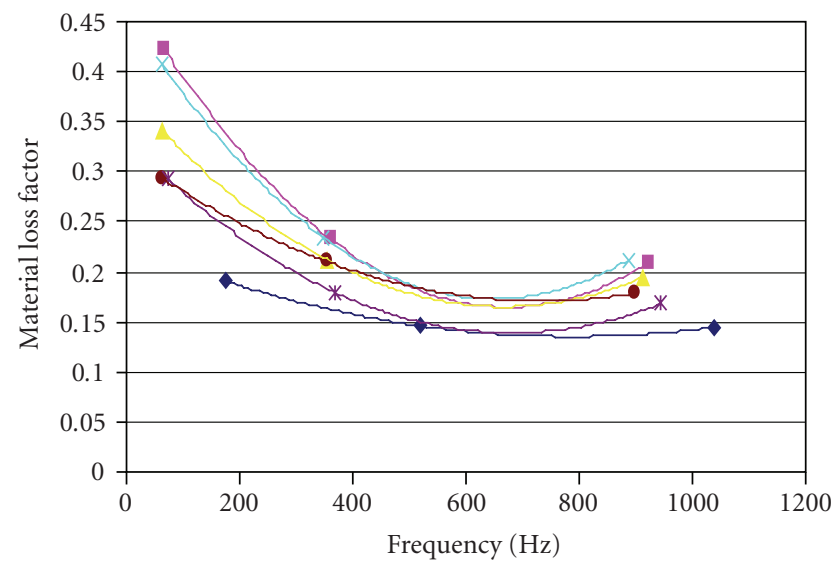

- R690-64 no.1 center impedance data

- Oberst data

R690-64 no. 2 center impedance data

$\times$ R690-64 no.3 center impedance data

- 4 wk R690-64 40 deg center impedance data

* 3 wk R690-64 40 deg center impedance data

Figure 9: Material loss factor at room temperature.

agreement with experimentally observed values in terms of predicting the natural frequencies of the beams with thicker coating. It may again be noted that the Oberst method does not permit testing of damping material coated onto nonmagnetic materials or use thick coating whether attached to magnetic or nonmagnetic beams. The Center Impedance method does not have these limitations. One

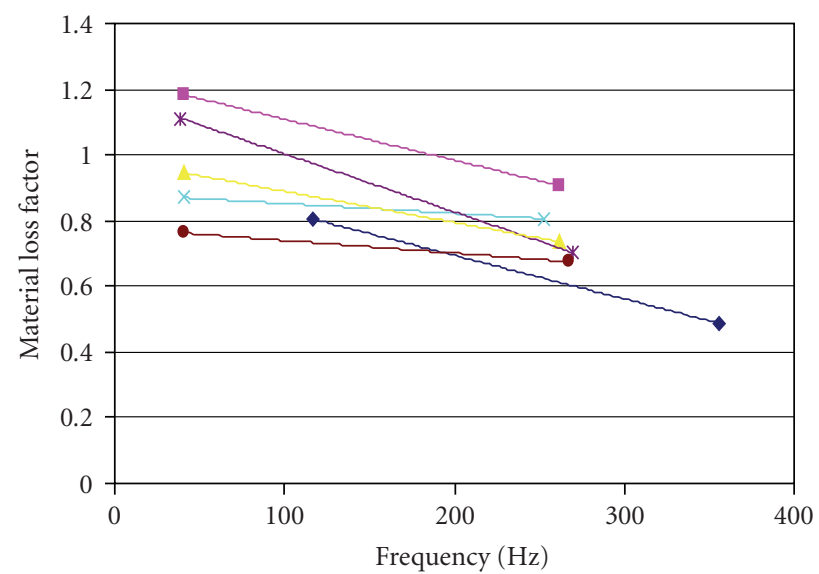

- R690-64 no. 1 center impedance data

- Oberst data

R690-64 no.2 center impedance data

R690-64 no.3 center impedance data

* 3 wk R690-64 40 deg center impedance data

- 4 wk R690-64 40 deg center impedance data

Figure 10: Material loss factor at $40^{\circ} \mathrm{C}$.

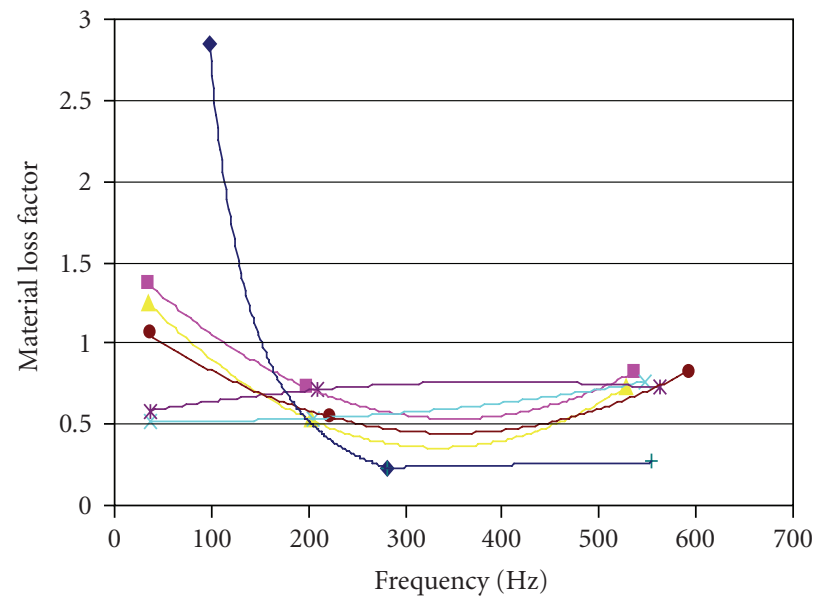

- R690-64 no. 1 center impedance data

- Oberst data

$\Delta$ "R690-64 no. 2 center impedance data

$x$ "R690-64 no.3 center impedance data

* 3 wk R690-64 40 deg center impedance data

- 4 wk R690-64 40 deg center impedance data

Figure 11: Material loss factor at $60^{\circ} \mathrm{C}$.

limitation of Center Impedance method is that results are available at only odd numbered modes because this method involves excitation of a free-free beam at the center. Also care should be taken to place the shaker stinger at the center properly in order to avoid excitation of torsional modes. Considering the importance of accurately measuring the properties of damping materials, it is suggested that new 


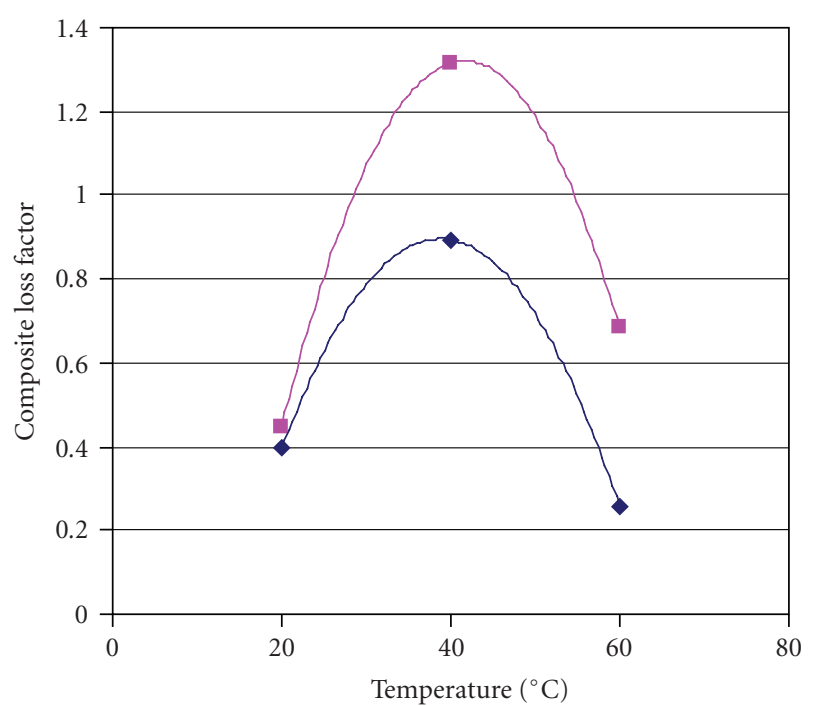

- R690-64 S.no.1

R690-64 S.no.4

Figure 12: Variation of composite loss factor with thickness at various temperatures.

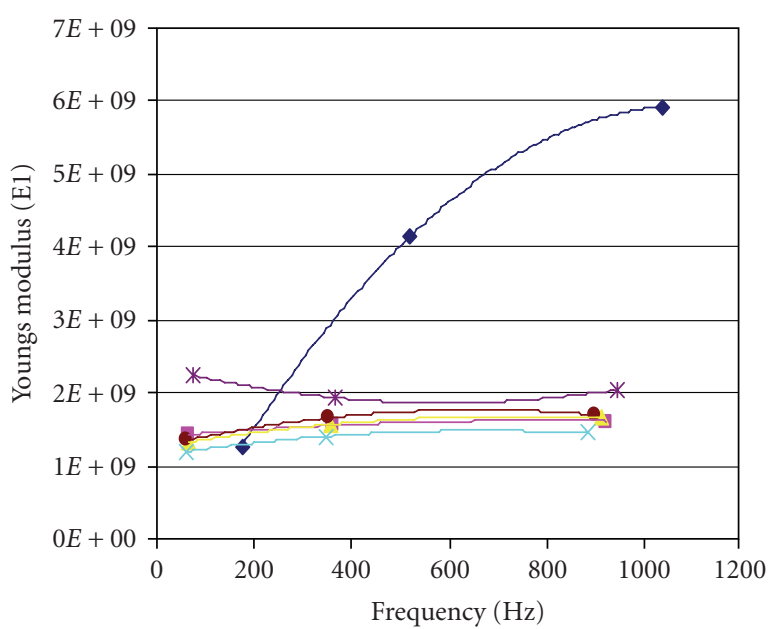

- Oberst bar data

- R690-64 no.1 center impedance data

$\triangle$ R690-64 no.2 center impedance data

$\times$ R690-64 no.3 center impedance data

- 4 wk R690-64 40 deg center impedance data

* 3 wk R690-64 40 deg center impedance data

FIGURE 13: Material Young's modulus (in $\mathrm{N} / \mathrm{m}^{2}$ ) at room temperature.

damping measurement standards be established based on the Center Impedance instead of the Oberst method. Future work is suggested to use this technique for several more types of damping materials and also utilize the properties obtained through this method to predict behavior of plates or more complicated structures.

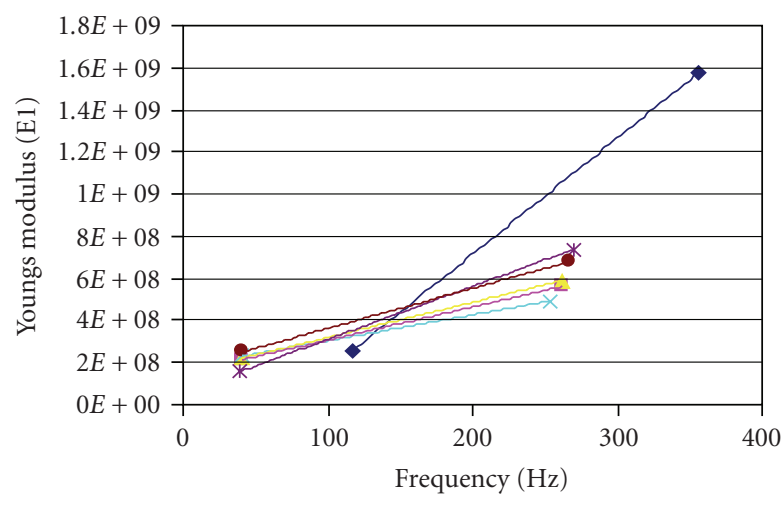

- Oberst bar data

- R690-64 S.no.1 center impedance data

"R690-64 S.no. 2 center impedance data

x "R690-64 S.no.3 center impedance data

* 3 wk "R690-64 40 deg center impedance data

- 4 wk R690-64 40 deg center impedance data

Figure 14: Material Young's modulus (in $\mathrm{N} / \mathrm{m}^{2}$ ) at $40^{\circ} \mathrm{C}$.

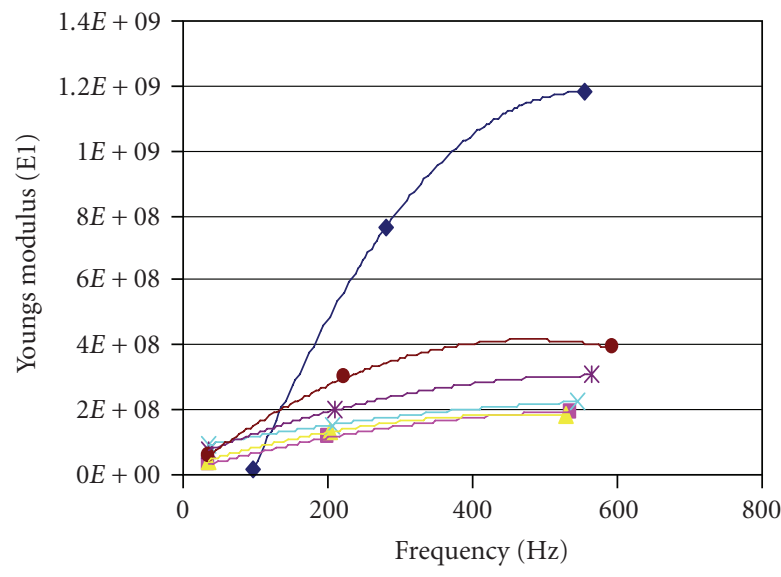

- Oberst bar data

- R690-64 S.no.1 center impedance data

R690-64 S.no.2 center impedance data

$\times$ R690-64 S.no.3 center impedance data

* 3 wk R690-64 40 deg center impedance data

- 4 wk R690-64 40 deg center impedance data

Figure 15: Material Young's modulus (in $\mathrm{N} / \mathrm{m}^{2}$ ) at $60^{\circ} \mathrm{C}$.

\section{Nomenclature}

$\alpha:\left(f_{c} / f_{n}\right)^{2}(1+D T)$

$\beta: \quad 4+6 T+4 T^{2}$

$D: \rho_{1} / \rho$, density ratio

A: Area of the beam, $\mathrm{m}^{2}$

$E$ : Young's modulus of bare bar, $\mathrm{N} / \mathrm{m}^{2}$

$E_{1}$ : Young's modulus of damping material, $\mathrm{N} / \mathrm{m}^{2}$ 
$H$ : Thickness of bare bar, $m$

$H_{1}$ : Thickness of damping material, $m$

I: $\quad$ Moment of inertia of the beam, $\mathrm{m}^{4}$

$M: \quad E_{1} / E$, Young's modulus ratio

$T: \quad H_{1} / H$, thickness ratio

$\eta_{1}$ : Loss factor of visco-elastic material, dimensionless

$\eta_{c}: \Delta f_{c} / f_{c}$, loss factor of composite bar, dimensionless

$\rho: \quad$ Density of Oberst bar, $\mathrm{kg} / \mathrm{m}^{3}$

$\rho_{1}$ : Density of damping material, $\mathrm{kg} / \mathrm{m}^{3}$

$\Delta f_{c}$ : Half-power bandwidth for mode $s$ of composite bar, $\mathrm{Hz}$

$f_{n}$ : Resonance frequency for mode $n$ of bare bar, $\mathrm{Hz}$

$f_{c}$ : Resonance frequency for mode $c$ of composite bar, $\mathrm{Hz}$

c: Index number: $1,2,3$, etc.

$l$ : $\quad$ Length of bar, $\mathrm{m}$.

\section{Acknowledgments}

The supports from US Department of Education Grant no. P116-Z08-0102, the Dean of NIU College of Engineering and Engineering Technology, and Daubert Chemicals are acknowledged.

\section{References}

[1] G. R. Kathawate and D. P. Sophiea, "Performance benefits of a new spray applied automotive damping material," in Proceedings of the International Body Engineers Conference, Stuttgart, Germany, 1997.

[2] ASTM Designation: E 756-93, Standard Test Method for Measuring Vibration-Damping Properties of Materials, Annual Book of ASTM Standards, vol. 04.06, pp. 827-833, 1993.

[3] "Laboratory measurement of the composite vibration damping properties of materials on a supporting steel bar," Tech. Rep. J1637, SAE, Troy, Mich, USA, 2007.

[4] L. F. Nielsen, N. J. Wismer, and S. Gade, "Improved Method for Complex Modulus Estimation," Bruel \& Kjaer Application Note, pp. 1-7, 1997.

[5] A. Gupta, S. Khandaswamy, S. Yellepeddi, T. Mulcahy, and J. Hull, "Dynamic modulus estimation and structural vibration analysis," in Proceedings of the 17th International Modal Analysis Conference (IMAC '99), pp. 1423-1427, Kissimmee, Fla, USA, February 1999.

[6] "Test methods for vibration-damping property in laminated damping steel sheets of constrained type," Tech. Rep. JIS G 0602, Japanese Standards Association, Tokyo, Japan, 1993.

[7] "ISO 16940:2008 Glass in building-Glazing and airborne sound insulation-Measurement of the mechanical impedance of laminated glass," International Organization for Standardization, Geneva, Switzerland, 2008.

[8] A. Gupta, S. Gadi, G. R. Kathawate, F. Fey, and D. Larson, "Effectiveness of a sprayable damper studied using multiple test methods," in Proceedings of the 23rd International Modal Analysis Conference, pp. 1-6, Orlando, Fla, USA, February 2005, paper no. 244.

[9] R. Pintelon, P. Guillaume, S. Vanlanduit, K. De Belder, and Y. Rolain, "Identification of Young's modulus from broadband modal analysis experiments," Mechanical Systems and Signal Processing, vol. 18, no. 4, pp. 699-726, 2004.

[10] ISO/PAS standard 16940:2004(E), Glass in building-Glazing and Airbone Sound Insulation-Measurement of Mechanical Impedance of Laminated Glass, 2004.

[11] J. M. Dowling and P. Saha, "A correlation between oberst bar and center point damping results," in Proceedings of the SAE Noise and Vibration Conference, St. Charles, Ill, USA, May 2009, paper no. 2009-01-2134.

[12] "Vibration damping materials and underbody coatings," Tech. Rep. J671, SAE, Troy, Mich, USA, 1997.

[13] J. Chahine and P. Saha, "Rationale for a standardized vibration damping test procedure for automotive applications," in Proceedings of the International Congress and Exposition, February 1992, SAE paper no. 9204606.

[14] A. D. Nashif, D. I. G. Jones, and J. P. Henderson, Vibration Damping, John Wiley \& Sons, New York, NY, USA, 1985.

[15] S. S. Rao, Mechanical Vibration, Prentice-Hall, Englewood Cliffs, NJ, USA, 4th edition, 2004.

[16] P. Tathavedkar, T. Onsay, and W. Liu, "Damping Performance Measurement of Non-Uniform Damping Treatments," SAE paper no. 2007-01-2199, 2007.

[17] M. Bolduc and N. Atalla, "Measurements of SEA damping loss factor for complex structures," Tech. Rep. 2005-01-2327, SAE, Traverse City, Mich, USA, 2005. 

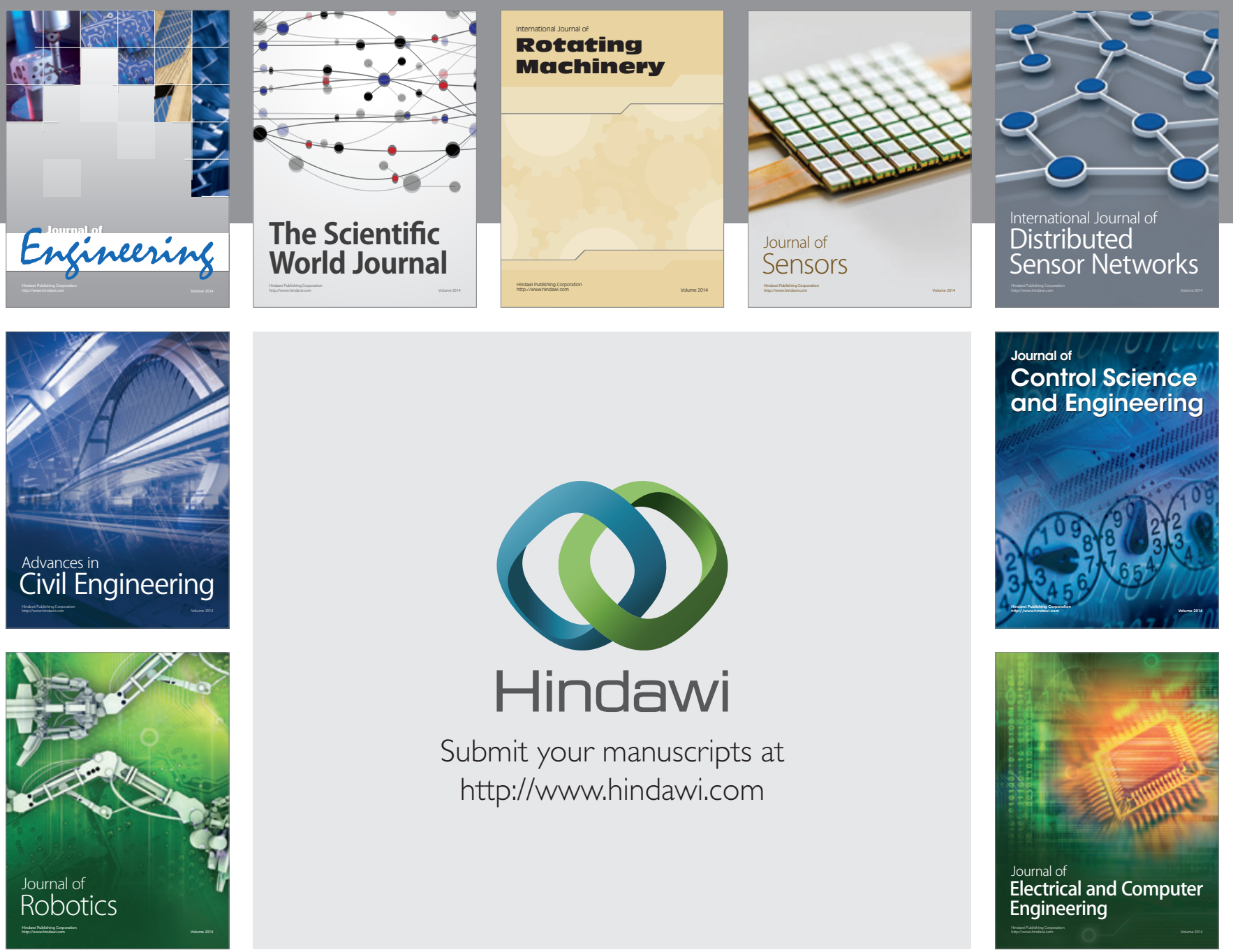

Submit your manuscripts at

http://www.hindawi.com
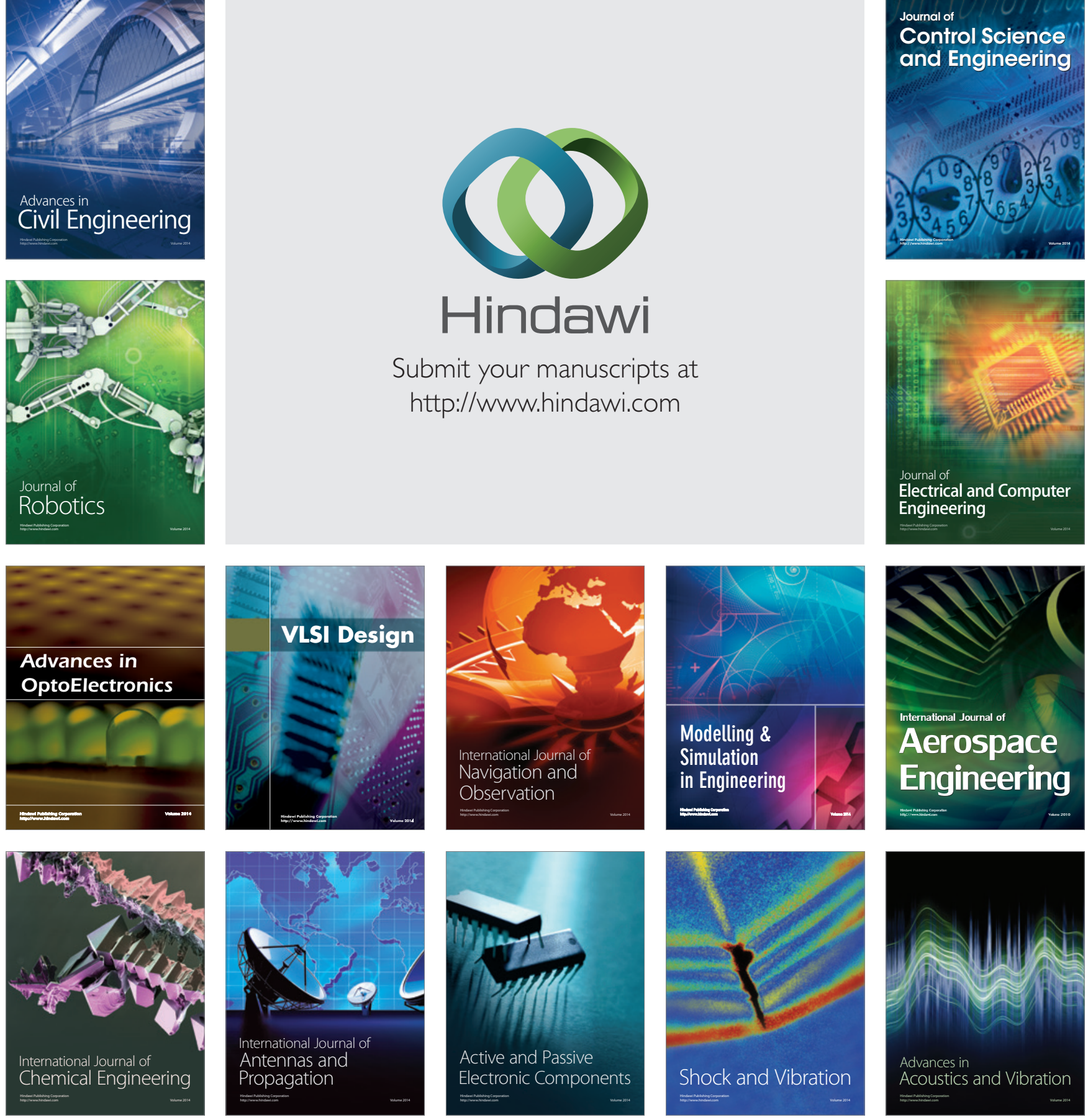